\title{
Penerapan Metode Simple Additive Weighting (SAW) pada Sistem Informasi Pemilihan Asisten Praktikum
}

\author{
Muhamad Azrino Gustalika, ${ }^{1, *}$, Diovianto Putra Rakhmadani ${ }^{2}$, Alon Jala Tirta Segara ${ }^{2}$ \\ ${ }^{1}$ Fakultas Informatika, Prodi Teknik Informatika, Institut Teknologi Telkom Purwokert, Purwokerto, Indonesia \\ ${ }^{2}$ Fakultas Informatika, Prodi Rekayasa Perangkat Lunak, Institut Teknologi Telkom Purwokerto, Purwokerto, Indonesia \\ Email: 1,"*azrino@ittelkom-pwt.ac.id, ${ }^{2}$ diovianto@ittelkom-pwt.ac.id, ${ }^{3}$ alon@ittelkom-pwt.ac.id \\ Email Penulis Korespondensi: azrino@ittelkom-pwt.ac.id
}

\begin{abstract}
Abstrak-Setiap kampus memiliki teknologi yang digunakan dalam melakukan komunikasi dan bertukar informasi dengan menggunakan teknologi berupa website. Penggunaan website sendiri sudah merambah ke dunia pendidikan, salah satunya laboratorium yang ada di kampus. Laboratorium di kampus tidak terlepas dari adanya asisten praktikum. Setiap semester fakultas informatika membuka pendaftaran untuk asisten praktikum, akan tetapi adanya kendala bahwa calon yang mendaftar masih menggunakan cara manual dalam seleksinya.sehingga membutuhan metode Simple Additive Weighting (SAW). Penelitian ini menggunakan metode Simple Additive Learning yang akan meningkatkan tingkatan nilai tertinggi sebesar 1,39 dengan indikator bobot yang digunakan dalam pemilihan asisten praktikum serta mendapatkan rata-rata skor sebesar 4.9 dari 5.0 sehingga, sangat efektif digunakan para admin (laboran) dalam mengelola dan dosen untuk melihat rekomendasi calon asisten praktikum, terbaik berbasis web.
\end{abstract}

Kata Kunci: asisten praktikum; Simple Additive Weighting; Website; Laboratorium; Informatika

Abstract-Each campus has technology that is used to communicate and exchange information using technology in the form of a website. The use of the website itself has penetrated into the world of education, one of which is the laboratory on campus. Laboratory on campus cannot be separated from the existence of a practicum assistant. Every semester the faculty of informatics opens registration for practicum assistants, but there are obstacles that candidates who register still use the manual method in their selection. So they need the Simple Additive Weighting (SAW) method. This study uses the Simple Additive Learning method which will increase the highest score level of 1.39 with the weight indicator used in the selection of practicum assistants and get an average score of 4.9 out of 5.0 so that it is very effective for admins (laborers) to manage and lecturers, to see recommendations for prospective practicum assistants, the best are web-based.

Keywords: Assistant Practikum; Simple Additive Weighting; Website; Laboratory; Informatics

\section{PENDAHULUAN}

Setiap manusia di belahan dunia manapun dapat melakukan komunikasi dan bertukar informasi dengan menggunkaan kemajuan teknologi masa kini[1]. Salah satu teknologi yang bisa digunakan yaitu website. Website adalah alamat didalam suatu web yang dapat memunculkan sejumlah gambar, teks, video, bahkan animasi[2]. Penggunaan website sendiri merambah ke dunia pendidikan, termasuk pada website kampus yang sedang menjadi tren di dunia pendidikan dan mendapatkan perhatian dan tanggapan yang bagus dari berbagai pihak [3]. Salah satunya dari laboratorium yang ada di kampus. Laboratorium di kampus digunakan untuk melaksanakan kegiatan praktikum. Kegiatan praktikum bertujuan untuk mengembangkan kompetensi mahasiswa yang ada mata kuliah tertentu, sehingga mahasiwa tidak hanya mendapatkan teori, akan tetapi juga mendapatkan praktikum[4]. kegiatan praktikum didampingi oleh asiten praktikum, assiten praktikum ini bertugas untuk membimbing mahasiswa dalam pelaksanaan kegiatan praktikum di laboratorium Institut Teknologi Telkom Purwokerto. Selama ini pemilihan asisten praktikum dilakukan dengan cara seleksi manual untuk mengemban tugas dalam membimbing praktikum, pada umumnya seleksi ini memerlukan penilaian yang tepat[5], akan tetapi hal ini berlaku apabila mahasiswa yang mendaftar untuk menjadi asisten praktikum dalam jumlah yang banyak. Menjadi problematika ketika mahasiswa hanya mendaftar ke mata kuliah yang disenangi atau hanya mempunyai kemampuan mata kuliah tertentu. Untuk mata kuliah yang tidak mendapatkan asisten praktikum menjadi tanggung jawab dosen sepenuhnya, hal ini menjadi tidak optimal dan efektif karena cara mengajar dosen dengan asisten praktikum jelas berbeda.penelitian ini mengunakan sistem pendukung keputusan yang dapat memabantu admin (laboran) dalam mengambil keputusan serta meningkatkan tingkat efektifitas dari keputusan yang di ambil oleh admin (laboran). Sistem pendukung keputusan yang digunakan pada penelitian ini adalah Simple Additive Learning (SAW) di mana metode ini mencari penjumlahan bobot dan rating yang digunakan oleh semua atribut sehingga hasil yang diperoleh dapat membatu admin (laboran) dalam keputusan akhir pemilihan asisten praktikum

Beberapa penelitian sebelumnya tentang pemilihan assiten praktikum atau asisten laboratorium di antaranya oleh maryamah tentang implementasi naïve bayes untuk seleksi asisten praktikum pada simulasi hadoop yang memberika hasil sebesar $80 \%$, akan tetapi memiliki kekurangan berupa data yang diperlukan harus lebih banyak[6]. Kemudian penelitian milik Abed Nego tentang seleksi penerimaan assiten praktikum menggunakan sistem pendukung keputusan dengan metode fuzzy Tsukamoto yang dapat membantu proses perekrutan calon asisten praktikum dengan cepat dan akurat, tapi metode ini memiliki beberapa kelemahan yaitu memerlukan variable dan himpunan fuzzy yang lebih banyak agar mendapatkan akurasi tertinggi[4]. Sedangkan Yaya Sulviyana meneliti tentang pemilihan asisten praktikum dengan menggunakan metode Simple Multi Attribute 
Rating Technique yang memudahkan pengelola dalam mengambil keputusan untuk mendapatkan asisten praktikum yang terbaik, akan tetapi metode ini memiliki kekurangan yaitu mengharuskan adanya variable dan kriteria yang dibutuhkan oleh sistem[5]. Alfa Saleh juga meneliti tentang penerapan metode SMARTER dalam penerimaan assiten laboratorium yang memperoleh akurasi sebesar 80\% dalam seleksi asisten laboratorium, metode ini memiliki kelemahan yaitu jumlah data yang dapat ditingkatkan agar mendukung efektifitas hasil memberikan kepercayaan bagi pembuat keputusan[7].Penelitian Tati Mardiana tentang pemilihan asisten laboratorium menggunkan metode TOPSIS-AHP yang menampilkan tingkat akurasi sebesar 90\%, tetapi perlu proses analisa data dalam pemilihan kriteria yang dibutuhkan[8]. Prind Triajeng Pungkasanti meneliti penerimaan asisten praktikum menggunakan metode profile matching yang berguna untuk pendukung keputusan dan bukan sebagai pengambil keputusan[9].

Fakultas Informatika (FIF) merupakan salah satu fakultas yang ada Institut Teknologi Telkom Purwokerto. FIF memiliki laboratorium yang digunakan sebagai kegiatan praktikum dan setiap semesternya FIF selalu membuka pendaftaran untuk mahasiwa yang berminat menjadi asisten praktikum, dari beberapa penelitian terdahulu dapat diuraikan bahwa selama ini pemilihan asisten praktikum masih dilakukan dengan cara manual dan tidak efektif dalam perhitungannya. Kondisi ini menimbulkan masalah karena tidak adanya penilaian pasti dalam pemilihan asisten praktikum. Berdasarkan permasalahan tersebut, diperlukan teknologi yang dapat membantu proses pemilihan asisten praktikum agar dapat menghasilkan keputusan yang terbaik bagi yang diterima. Teknologi tersebut berupa metode Simple Additive Learning yang digunakan dalam memecahkan masalah dalam pemilihan asisten praktikum dengan menggunakan kriteria yang digunakan dalam penelitian ini antara lain nilai akademik (IPK), nilai microteaching, nilai keprbadian, dan nilai wawancara.

\section{METODOLOGI PENELITIAN}

\subsection{Tahapan Penelitian}

Pada kasus ini, peneliti akan menggunakan metode Simple Additive Weighting (SAW) dalam pengembangan perangkat lunak dan pemrograman web, dimana nanti akan menghasilkan keputusan terbaik dalam pemilihan asisten praktikum berbasis web.

\subsection{Metode Waterfall}

Pada pengembangan perangkat lunak, peneliti menggunkan metode Waterfall Model. Metode ini digunakan menjabarkan hasil penelitian[10]. Dalam arti yang yang lain, metode ini disebut "Classic life Cyle", dimana menggunakan pendekatan yang berurutan dan sistematis pada pengembangan perangkat lunak[11]. Metode waterfall memiliki tahapan yang terdiri dari analisa, desain, implementasi, uji coba, dan pemeliharaan[12].

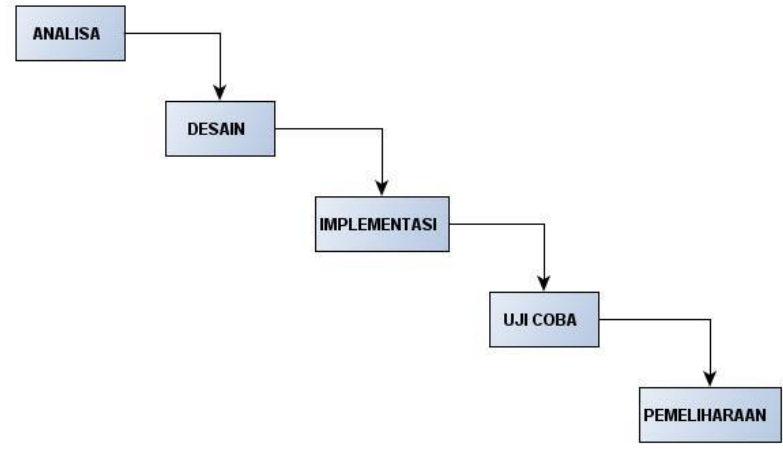

Gambar 1. Metode Waterfall

Pada gambar 1 menjelaskan bagaiamana metode waterfall bekerja. Dalam penelitian ini ada beberapa langkah yang dilakukan dari analisa kemudian desain, implementasi, uji coba, dan pemeliharaan. Dalam penelitian ini penulis menggunakan proses pengmbangan waterfall sebagai pola pengembangan sistem.berikut tahapannya:

1. Analisa Kebutuhan

Pada tahapan ini dilakukan analisis kebutuhan terhadap sistem asisten praktikum. Pengumpulan data dilakukan dengan cara wawancara dosen, tenaga asisten praktikum, dan pihak terkait lainny. Selain itudata juga didapat dari dokumen kebutuhan asisten praktikumdi Institut Teknologi Telkom Purwokerto dan juga Analisa gap dengan kebutuhan saat ini.

2. Desain

Pada tahap ini merancang desain dari sistem yang akan dibuat dengan menggunakan usecase diagram, activity diagram serta Entity Relationship Diagram (ERD).

3. Implementasi 
Tahap implementasi atau penulisan kode program merupakan tahap setelah desain yang diterjemahkan ke dalam bentuk perangkat lunak dengan menggunakan perintah dari bahasa pemrograman berupa PHP dan basisdata berupa MySQL.

4. Ujicoba

Pada tahap ini sistem diuji untuk mengetahui kekurangan yang ada di dalam sistem dan menguji kinerja dan fitur yang telah selesai dibuat. Pengujian ini dilakukan oleh pembuat sistem dan user di mana menggunakan blackbox berdasarkan User Acceptance Testing (UAT) terhadap sistem yang telah dibuat.

5. Pemeliharaan

Pada tahapan pemeliharaan bertujuan untuk memastikan fitur berjalan dengan baik dan meminimalisir bug yang ada pada sistem serta melakukan update secara berkala.

\subsection{Metode Simple Additive Weighting (SAW)}

Pada penelitian ini, penulis menggunakan metode Simple Additive Weighting (SAW) untuk menghasilkan keputusan yang terbaik bagi penentuan asisten praktikum yang terpilih sesuai dengan indikator yang diinginkan. Simple Additive Weighting merupakan metode dalam menentukan penjumlahan yang berbobot dan menacari rating kinerja pada semua atribut[13]-[16]. Metode Simple Additive Weighting (SAW) memerlukan proses normalisasi matrik agar bisa di bandingkan dengan alternatif yang sudah ada [17]-[19].

$R_{i j}=\frac{x_{i j}}{\max _{i j}}$ Jika j adalah atribut benefit

$R_{i j}=\frac{\min _{i j}}{x_{i j}} \mathrm{Jika} \mathrm{j}$ adalah atribut cost

Keterangan:

$\mathrm{R}_{\mathrm{ij}} \quad$ : rating kinerja ternormalisasi

MAX $_{\mathrm{ij}}$ : nilai maksimum dari setiap baris dan kolom

$\mathrm{MIN}_{\mathrm{ij}}$ : nilai minimum dari setiap baris dan kolom

$\mathrm{X}_{\mathrm{ij}} \quad$ : baris dan kolom dari matriks dengan $\mathrm{r}_{\mathrm{ij}}$ merupakan rating kinerja ternormalisasi dari alternative Ai pada atribut $\mathrm{Cj} ; \mathrm{I}=1,2, \ldots \mathrm{m}$ dan $\mathrm{j}=1,2, \ldots ., \mathrm{n}$

benefit : jika nilai paling besar adalah yang terbaik

cost : jika nilai paling adalah yang terbaik

Nilai preferensi untuk setiap alternatif (Vi) adalah sebagai berikut:

$V i \sum_{j=1}^{n} W j R i j$

Keterangan:

Vi : Nilai akhir berupa rangking untuk setiap alternatif

$\mathrm{Wj} \quad$ : nilai bobot dari rangking yang telah ditetapkan

Rij : Rangking nilai matrik yang ternormalisasi maka Vi lebih besar yang mengindikasikan bahwa alternative Ai telah terpilih

\section{HASIL DAN PEMBAHASAN}

Pada penelitian ini, ada beberapa tahapan yang dilakukan oleh peneliti adalah menetukan kiteria penilaian, membuat activity diagram, usecase diagram serta Entity Relationship Diagram.

\subsection{Analisa}

Penelitian ini Pada bagian ini akan menganalisa mengapa FIF memerlukan asisten pendukung keputusan berupa Simple Additive Weighting $(S A W)$ untuk menentukan asisten praktikum. Pelamar harus memenuhi beberapa penilaian yang dibutuhkan untuk menjadi assiten praktikum, di antaranya akademik (IPK semester terakhir), microteaching, kepribadian, dan wawancara[5]. Berdasarkan nilai tersebut maka menghasilkan bobot W sebagai berikut:

Tabel 1. Tabel penilaian dan bobot

\begin{tabular}{lll}
\hline No & Penilaian & Bobot \\
\hline 1 & Akademik (IPK semester terakhir) & $20 \%$ \\
2 & Microteaching & $30 \%$ \\
3 & Kepribadian & $25 \%$ \\
4 & Wawancara & $25 \%$ \\
Total & & $100 \%$ \\
\hline
\end{tabular}


ISSN 2614-5278 (media cetak), ISSN 2548-8368 (media online)

Available Online at https://ejurnal.stmik-budidarma.ac.id/index.php/mib DOI 10.30865/mib.v5i3.3065

Pada tabel 1 menjelaskan tentang tabel penilaian dan bobot yang digunakan pada penelitian ini yang menghasilkan nilai akademik atau IPK sebanyak 20\%, microteaching 30\%, keprobadian 25\%, dan wawancara $25 \%$.

Dari menghasilkan nilai W sebagai berikut:

$$
\begin{array}{ll}
\mathrm{W} 1=\text { akademik (IPK semester terakhir) } & =20 \%=\frac{20}{100}=0,2 \\
\mathrm{~W} 2=\text { microteaching } & =30 \%=\frac{30}{100}=0,3 \\
\mathrm{~W} 3=\text { kepribadian } & =25 \%=\frac{25}{100}=0,25 \\
\mathrm{~W} 4=\text { wawancara } & =25 \%=\frac{25}{100}=0,25 \\
\text { Vektor bobot } \mathrm{W} & =[0,3 ; 0,2 ; 0,25 ; 0,25] ;
\end{array}
$$

Selanjutnya peneliti membuat tingkatan bobot dan nilai metode Simple Additive Weighting (SAW)

Tabel 2. Tingkatan bobot dan nilai

\begin{tabular}{lll}
\hline No & Bobot & Nilai \\
\hline 1 & Sangat Tinggi & 5 \\
2 & Tinggi & 4 \\
3 & Cukup & 3 \\
4 & Rendah & 2 \\
5 & Sangat Rendah & 1 \\
\hline
\end{tabular}

Pada tabel 2 menjelaskan tentang tingkatan bobot bernilai satu hingga lima yang dijadikan acuan dalam penelitian ini mulai dari sangat rendah, rendah, cukup, tinggi, dan sangat tinggi

1. Berikut kriteria dari akademik (IPK Terakhir):

Tabel 3. Nilai dari kriteria IPK terakhir

\begin{tabular}{lll}
\hline No & IPK & Nilai \\
\hline 1 & $3.5-4.0$ & 5 \\
2 & $3.0-3.5$ & 4 \\
3 & $2.5-3.0$ & 3 \\
4 & $2.0-2.5$ & 2 \\
5 & $1.5-2.0$ & 1 \\
\hline
\end{tabular}

Pada tabel 3 menjelaskan salah satu nilai kriteria pemilihan asisten praktikum pada penelitian ini yaitu akademik atau IPK terakhir yang terdiri dari ipk paling rendah dengan nilai 1.5 hingga nilai yang paling tinggi sebesar 4.0

2. Berikut merupakan kriteria dari microteaching:

Tabel 4. Nilai dari kriteria microteaching

\begin{tabular}{lll}
\hline No & Microteaching & Nilai \\
\hline 1 & Penguasaaan Materi & 5 \\
2 & Interaksi dengan mahasiswa & 4 \\
3 & Pengelolaan kelas & 3 \\
4 & Integrasi nilai-nilai karakter & 2 \\
5 & Pemilihan bahasa & 1 \\
\hline
\end{tabular}

Penelitian ini juga memakai kriteria dari microteaching dalam pengukuran nilai yang diperlihatkan pada tabel 4 yang berisi penguasaaan materi interaksi dengan mahasiswa, pengelolaan kelas, integrasi nilai-nilai karakter dan pemilihan bahasa

3. Berikut merupakan kriteria dari kepribadian:

Tabel 5. Nilai dari kriteria kepribadian

\begin{tabular}{lll}
\hline No & Kepribadian & Nilai \\
\hline 1 & Tanggung jawab & 5 \\
\hline
\end{tabular}


ISSN 2614-5278 (media cetak), ISSN 2548-8368 (media online)

Available Online at https://ejurnal.stmik-budidarma.ac.id/index.php/mib

DOI 10.30865/mib.v5i3.3065

\begin{tabular}{lll}
\hline No & Kepribadian & Nilai \\
\hline 2 & Santun & 4 \\
3 & Percaya diri & 3 \\
4 & Kompetitif & 2 \\
5 & Saling menghargai & 1 \\
\hline
\end{tabular}

Berikutnya pada tabel 5 kriteria yang diperlukan untuk penilaian menggunakan nilai keperibadian yang berisi nilai dari tanggung jawab, santun, percaya diri, kompetitif, dan saling menghargai

4. Berikut merupakan kriteria dari wawancara:

Tabel 6. Nilai dari kriteria wawancara

\begin{tabular}{lll}
\hline No & Wawancara & Nilai \\
\hline 1 & Pengalaman & 5 \\
2 & Pengetahuan & 4 \\
3 & Motivasi & 3 \\
4 & Gaji & 2 \\
5 & Sikap dan penampilan & 1 \\
\hline
\end{tabular}

Selanjutnya pada tabel 6 merupakan kriteria dari wawancara yang berisi nilai pengalaman, pengetahuan, motivasi, gaji, dan sikap penampilan

\subsection{Penerapan Metode SAW}

Dalam proses penyeleksian asisten praktikum, ada beberapa langkah yang harus dilakukan oleh peneliti:

1. Menentukan jenis kriteria

Pada tahapan ini peneliti membut kriteria sebagai berikut

$\mathrm{C} 1=$ akademik

$\mathrm{C} 2=$ microteaching

C3 = kepribadian

$\mathrm{C} 4=$ wawancara

2. Menentukan tingkatan bobot dan nilai

Pada tahapan ini peneliti membuat tingkatan nilai dan bobot seperti berikut:

$5=$ Sangat tinggi

$4=$ Tinggi

$3=$ Cukup

$2=$ Rendah

$1=$ Sangat Rendah

3. Menentukan nama calon yang akan dinilai berdasarkan dengan kriteria yang telah di tentukan

Pada tahapan ini menentukan nama calon dari assiten praktikum yang telah mendaftar:

A1 = Havinda Rosita Faradina

A2 = Vindi Eka Safitri

A3 = Ajeng Fitria Rahmawati

A4 = Siska Indah Wahyuni

4. Menentukan matrik keputusan dan menormalisasikannya

5. Menentukan penjumalahan dari perkalian matrik sebagai alternatif (Ai) terbaik

Pada tahapan ini membuat rating kecocokan dari setiap alternative pada setiap kriteria:

Tabel 7. Tingkat rating kecocokan pada alternative pada setiap kriteria

\begin{tabular}{llllll}
\hline \multirow{2}{*}{ No } & Alternatif & \multicolumn{2}{l}{ Kriteria } \\
\cline { 3 - 6 } & & C1 & C2 & C3 & C4 \\
\hline 1 & A1 & 5 & 3 & 4 & 2 \\
2 & A2 & 4 & 5 & 2 & 3 \\
3 & A3 & 3 & 4 & 5 & 5 \\
4 & A4 & 2 & 2 & 3 & 4 \\
\hline
\end{tabular}

Pada tabel 7 menjelaskan tentang tingkat kecocakan pada setiap alternative pada setiap kriteria yang digunakan. Tahapan selanjutnya keputusan yang ternormalisasikan dari matrik sebagai berikut:

1. Untuk $\mathrm{C} 1$

$r 11=\frac{5}{5}=1,0$ 
ISSN 2614-5278 (media cetak), ISSN 2548-8368 (media online)

Available Online at https://ejurnal.stmik-budidarma.ac.id/index.php/mib DOI 10.30865/mib.v5i3.3065

$r 12=\frac{3}{5}=0,6$
$r 13=\frac{4}{5}=0,8$
$r 14=\frac{2}{5}=0,4$

2. Untuk $\mathrm{C} 2$

$r 21=\frac{4}{4}=1,0$

$r 22=\frac{5}{4}=1,25$

$r 23=\frac{2}{4}=0,5$

$r 24=\frac{3}{4}=0,75$

3. Untuk C3

$r 31=\frac{3}{3}=1,0$

$r 32=\frac{4}{3}=1,33$

$r 33=\frac{5}{3}=1,6$

$r 34=\frac{5}{3}=1,6$

4. Untuk C4

$r 41=\frac{2}{2}=1,0$

$r 42=\frac{2}{2}=1,0$

$r 43=\frac{3}{2}=1,5$

$r 44=\frac{4}{2}=2$

Kemudian hasil normalisasi di buat kedalam matrik

$\begin{array}{llll}1,0 & 0,6 & 0,8 & 0,4 \\ 1,0 & 1,25 & 0,5 & 0,75 \\ 1,0 & 1,33 & 1,6 & 1,6 \\ 1,0 & 1,0 & 1,5 & 2\end{array}$

6. Menentukan proses perangkingan dengan bobot yang diberi oleh pengambil keputusan.

$W=0,2 \% ; 0,3 \% ; 0,25 \% ; 0,25 \%$;

Maka mendapatkan hasil perangkingan sebagai berikut

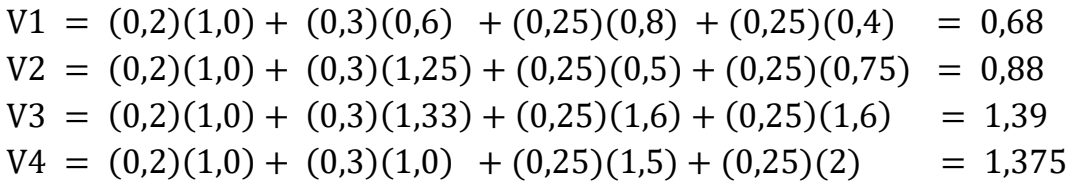

Dari perangkingan di atas, diperoleh hasil akhir perkalian dan perhitungan matrik dan dapat di simpulkan bahwa nilai tertinggi diperoleh degan kode V3 atas nama Ajeng Fitria Rahmawati dengan nilai 1,39 hasil implementasi penerapan metode, ataupun hasil dari pengujian metode.

\subsection{Use Case Diagram}

Dalam sistem yang digunakan peneliti menggunakan usecase. Usecase merupakan salah satu jenis diagram untuk mengembangkan sistem yang dibuat dalam menjelaskan interaksi antara aktor dan sistem [20]. 
ISSN 2614-5278 (media cetak), ISSN 2548-8368 (media online)

Available Online at https://ejurnal.stmik-budidarma.ac.id/index.php/mib DOI 10.30865/mib.v5i3.3065

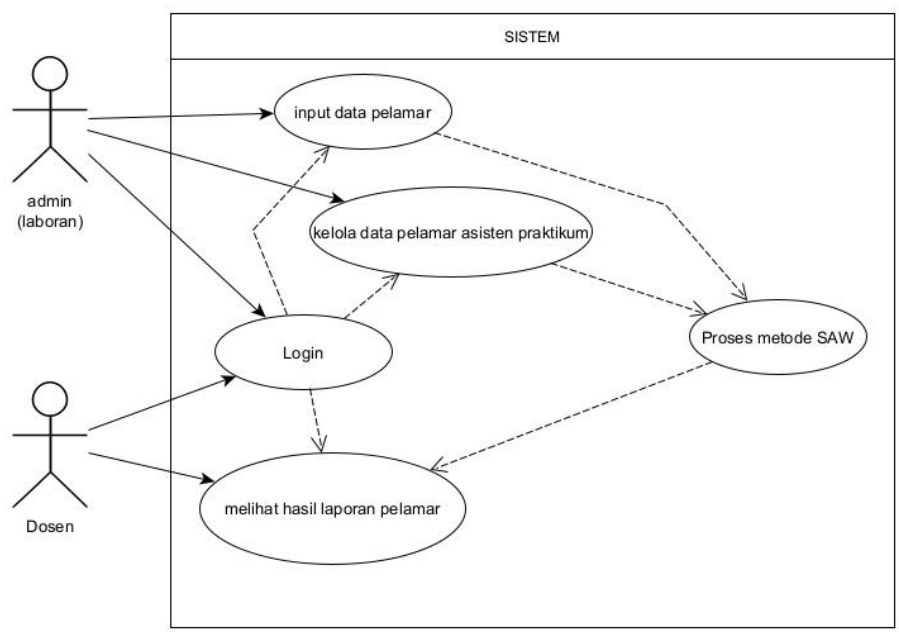

Gambar 2. Usecase diagram sistem

Pada gambar 2 menjelaskan usecase yang digunakan oleh peneliti dalam membangun sistem ini, ada dua aktor yang yang diperlukan dalam sistem ini yaitu aktor admin (laboran) dan dosen yang memiliki interaksi dengan sistem sesuai dengan model usecase tersebut

\subsection{Activity Diagram}

Activty diagram merupakan diagram yang berfungsi sebagai rangkaian aliran aktifitas pada sistem tersebut[21]. Pada penelitian ini ada dua activity yang digunakan yaitu activity diagram admin(laboran) dan dosen

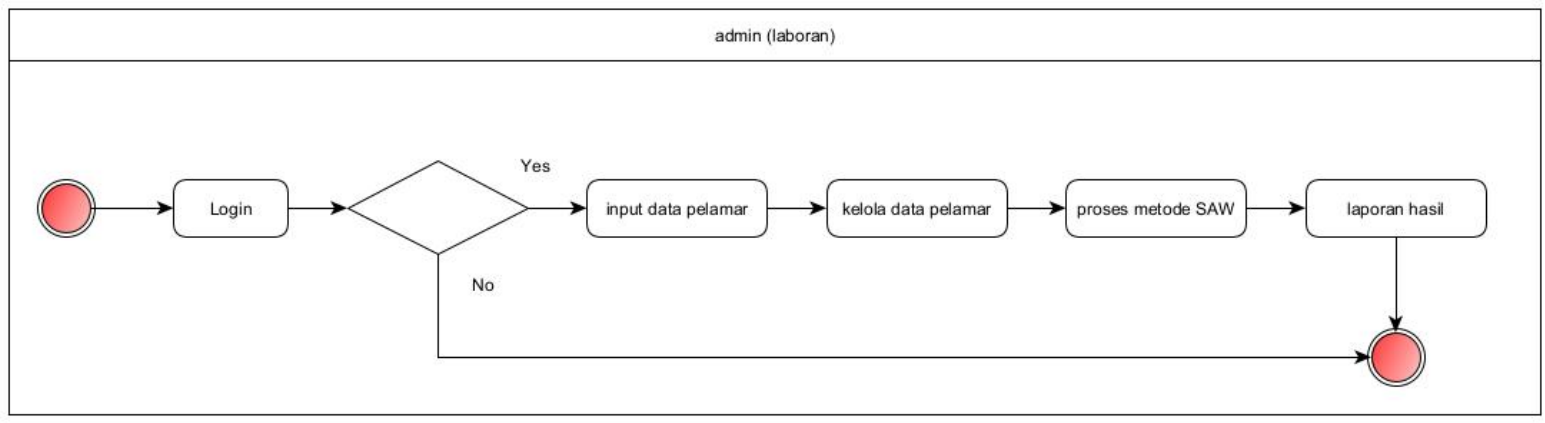

Gambar 3. Activity diagram admin

Pada gambar 3 menjelaskan activity yang di lakukan oleh admin (laboran) mulai dari memasukkan data pelamar, mengelola data pelamar serta menghasilkan laporan berdasarkan proses menggunkaan metode Simple Additive Weighting (SAW).

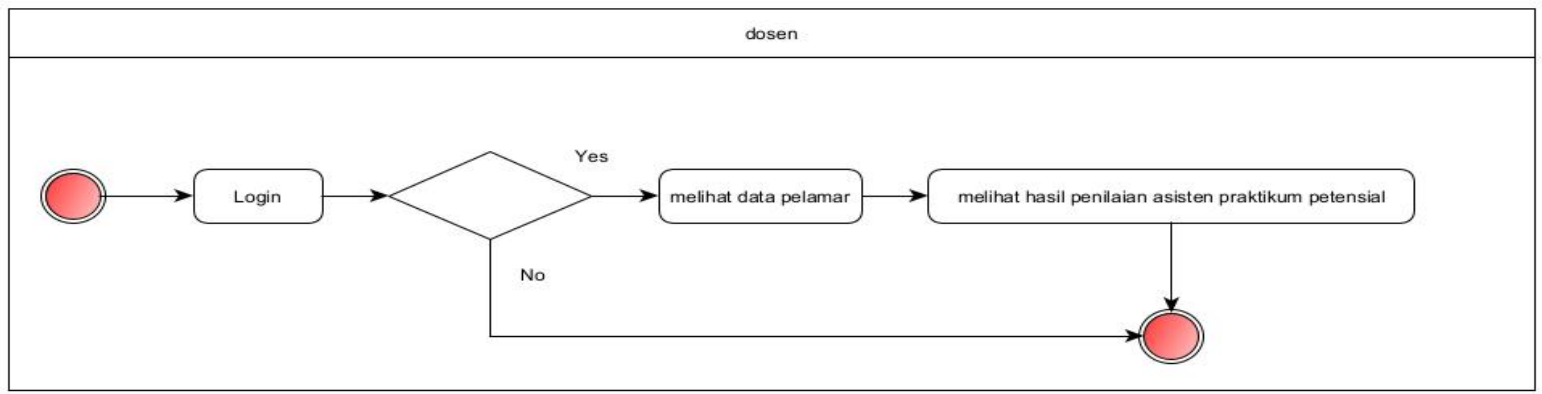

Gambar 4. Activity diagram dosen gambar 4

Pada activity diagram dosen melihat data pelamar dan hasil penilaian asisten praktikum seperti terlihat pada

\subsection{Entity Relationship Diagram}

Dalam sistem yang digunakan peneliti menggunakan Entity Relationship Diagram (ERD). Diagram ini bertujuan untuk menghubungkan database yang berisi objek-objek dalam sistes tersebut[22] 
ISSN 2614-5278 (media cetak), ISSN 2548-8368 (media online)

Available Online at https://ejurnal.stmik-budidarma.ac.id/index.php/mib DOI 10.30865/mib.v5i3.3065

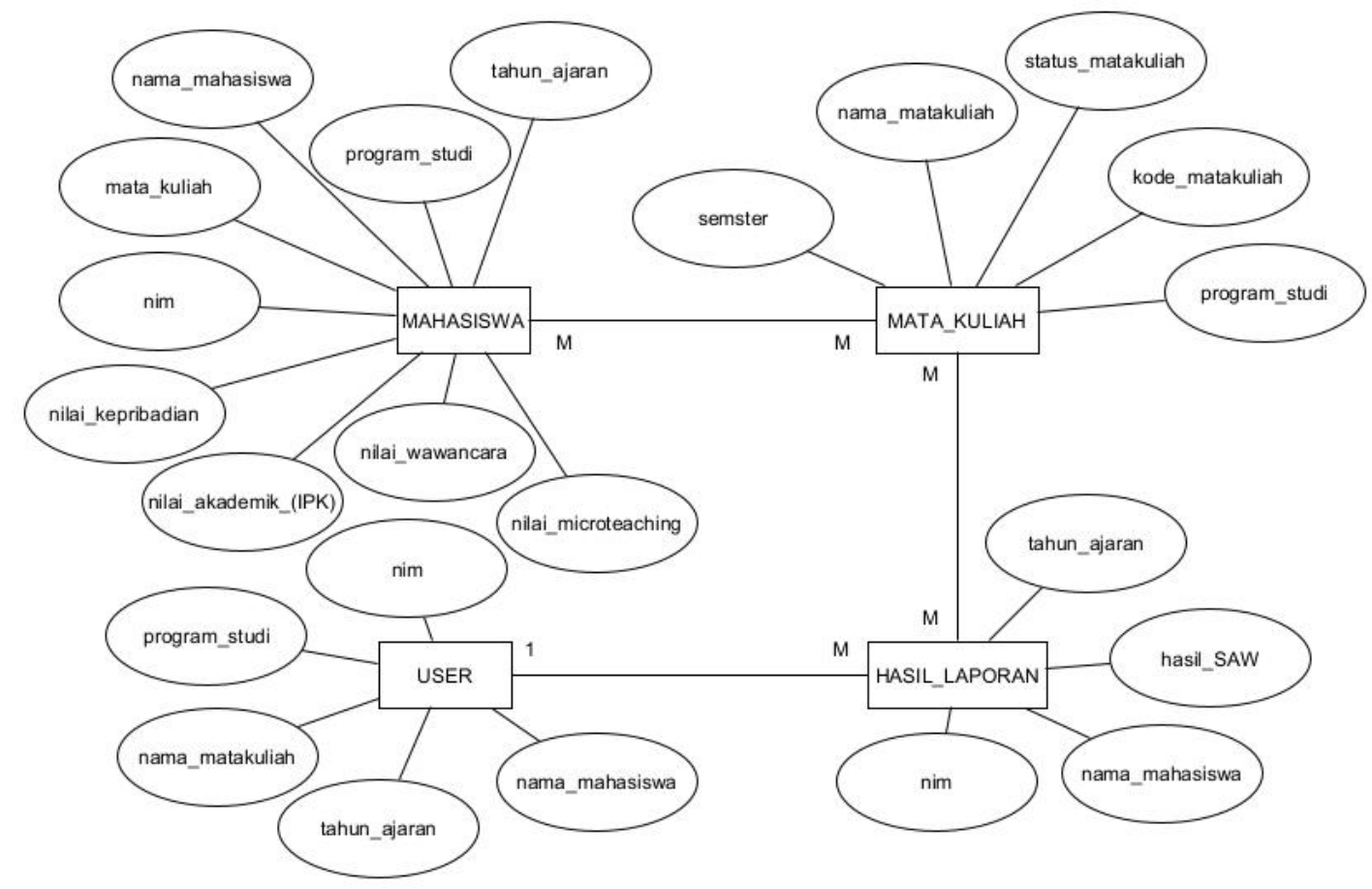

Gambar 5. Entity Relationship Diagram

Pada ERD menggunakan database yang di perlukan untuk sistem ini jadi yang diperlukan dalam penelitian ada empat entitas yang diperlukan berupa mahasiswa, mata_kuliah, hasil_laporan, dan user

\subsection{Tampilan Hasil}

Pada halaman website, tampilan awal berupa halaman login untuk admin (laboran) dan dosen

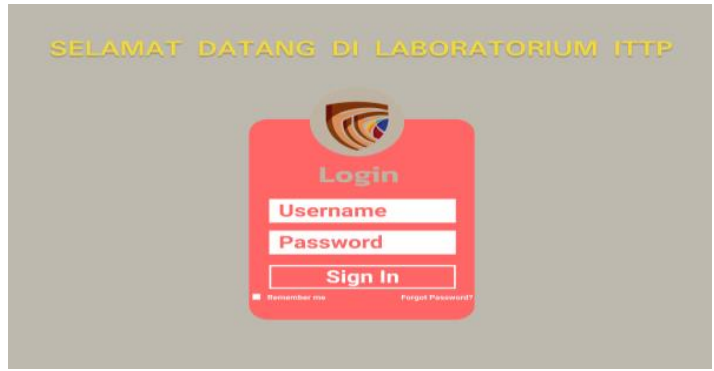

Gambar 6. Tampilan halaman login

Pada gambar 6 menjelaskan tentang halaman login admin dan dosen memasukkan username beserta password untuk verifikasi pengguna dengan id dan password yang telah diberikan. Setelah berhasil melakukan login, maka akan muncul tampilan awal program

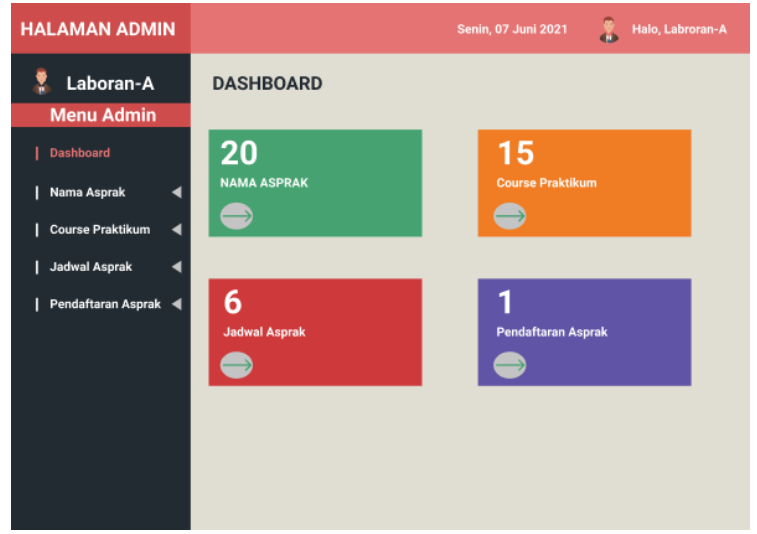

Gambar 7. Tampilan dashboard admin

Muhamad Azrino Gustalika, Copyright (C2021, MIB, Page 820 
JURNAL MEDIA INFORMATIKA BUDIDARMA

Volume 5, Nomor 3, Juli 2021, Page 813-823

ISSN 2614-5278 (media cetak), ISSN 2548-8368 (media online)

Available Online at https://ejurnal.stmik-budidarma.ac.id/index.php/mib

DOI 10.30865/mib.v5i3.3065

Ketika admin berhasil login, maka muncul halaman utama atau dashboard khusus untuk menu admin seperti terlihat pada gambar 7

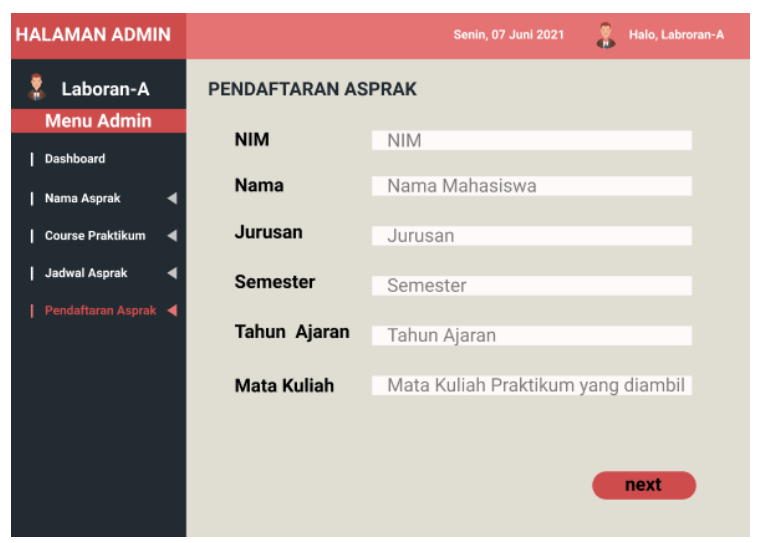

Gambar 8. Tampilan halaman pendaftaran asisten praktikum

Pada gambar 8 admin (laboran), akan memasukkan data calon mahasiswa assisten praktikum pada halaman pendaftaran assisten praktikum

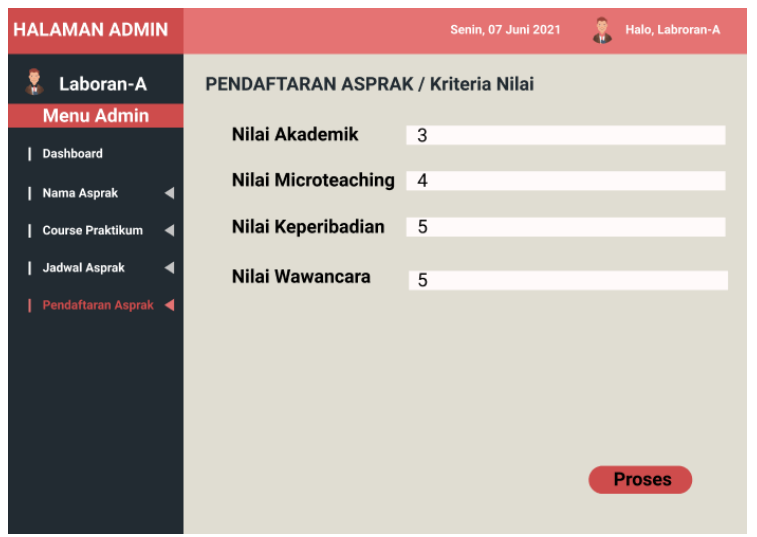

Gambar 9. Tampilan halaman kriteria nilai

Setelah memasukkan data mahasiswa kemudian diproses sehingga masuk ke halaman kriteria nilai dan admin memasukkan nilai yang di peroleh calon asisten praktikum seperti terlihat pada gambar 9 .

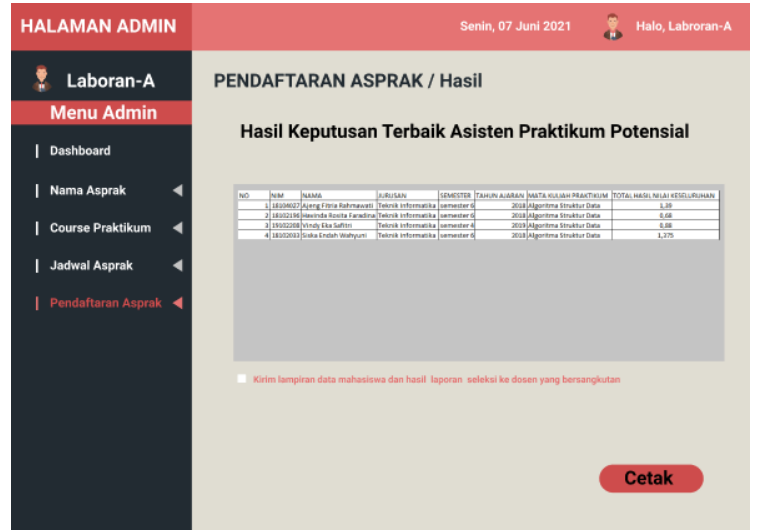

Gambar 10. Tampilan hasil pada halaman admin

Pada gambar 10 merupakan hasil keputusan terbaik asisten praktikum yang telah diproses menggunakan metode Simple Additive Weighting $(S A W)$. Hasil perhitungan yang digunakan dalam sistem ini sama dengan perhitungan manual. 
ISSN 2614-5278 (media cetak), ISSN 2548-8368 (media online)

Available Online at https://ejurnal.stmik-budidarma.ac.id/index.php/mib DOI 10.30865/mib.v5i3.3065

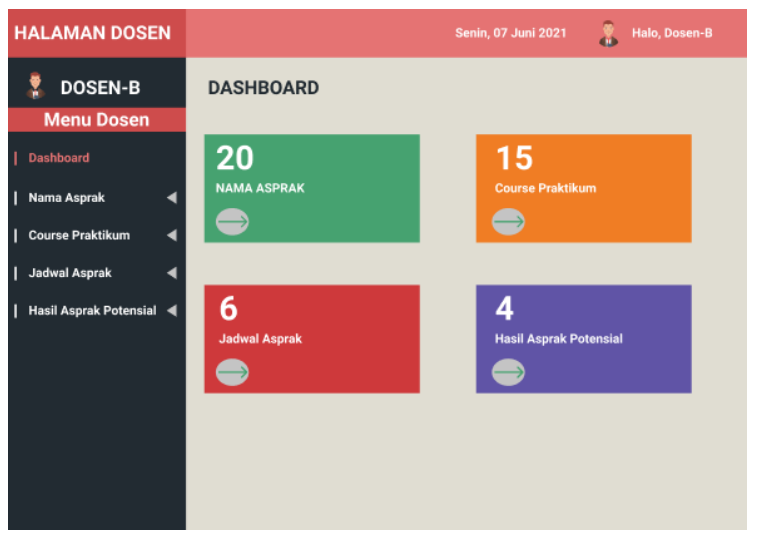

Gambar 11. Tampilan dashboard dosen login.

Pada gambar 11 menunjukkan tampilan halaman dashboard dosen, yang muncul ketika dosen telah berhasil

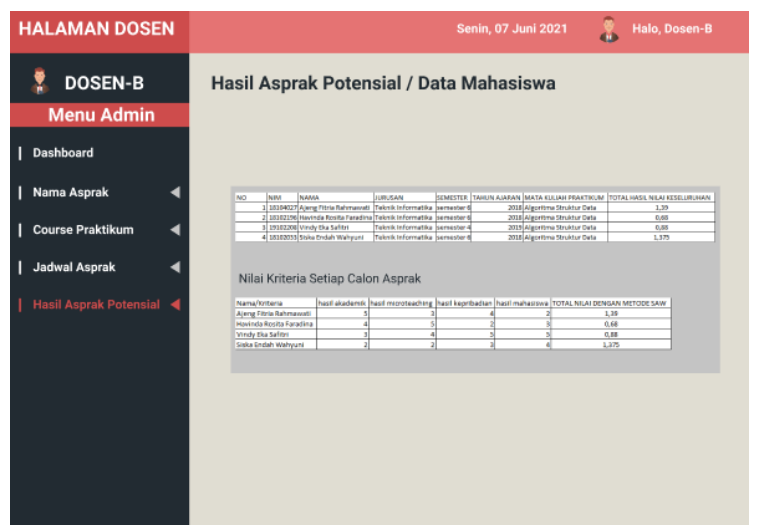

Gambar 12. Tampilan hasil asisten praktikum potensial

Pada halaman dosen muncul laporan hasil assiten praktikum potensial dari halaman admin berdasarkan dari nilai kriteria yang dibutuhkan dan hasil perhitungan dari sistem ini sama dengan hasil perhituangan sistem milik admin (laboran), maupun perhitungan manualnya

\subsection{Pengujian Blackbox}

Berdasarkan hasil pengujian blackbox yang dilakukan dalam sistem pencarian asisten praktikum potensial didapatkan bahwa sistem telah berjalan dengan baik secara fungsional maupun secara kegunaan.

\section{a. User Acceptance Testing (UAT)}

Pada aplikasi ini menggunakan user acceptance testing (rataan) yang diperlukan dalam pengujian ini dengan menggunakan kuisoner yang dilakukan terhadap 20 orang dosen, dan didapati bahwa

Tabel 8. User acceptence tesing (rataan)

\begin{tabular}{lll}
\hline No & Deskripsi & Skor rataan (Skala 1-5) \\
\hline 1 & Sistem mudah digunakan & 5 \\
2 & Tidak terdapat bug di dalam sistem & 5 \\
3 & Tampilan sistem mudah dipahami & 4.5 \\
4 & Pengelolaan mudah untuk diterima & 5 \\
5 & $\begin{array}{l}\text { Hasil dari pengolahan sistem mampu } \\
\text { digunakan sebagai pengambilan keputusan }\end{array}$ & 5 \\
Rata-rata skor rataan & 4,9 \\
\hline
\end{tabular}

Berdasarkan hasil pengujian user acceptance pada tabel 8 dengan pengambilan skor menggunakan skala likert dengan angka 1 sebagai nilai yang paling rendah hingga angka 5 yang paling tinggi dengan responden sebanyak 20 orang dosen selaku pengguna sistem. Didapati bahwa terdapat rataan untuk butir pernyataan nomor 1 sebesar 5.0, sedangkan untuk butir nomor 2 mendapatkan rataan sebanyak 4.5 . kemudian untuk butir pernyataan 3,4,5 mempunyai hasil skor yang sama sebesar 5.0 


\section{KESIMPULAN}

Berdasarakan sistem yang telah di buat maka sistem ini terbukti dapat membantu dosen dan laboran dalam aktifitas pencarian asisten praktikum yang potensial di lingkungan kampus Institut Teknologi Telkom Purwokerto. Penerapan metode Simple Additive Weighting (SAW) terbukti dengan menghasilkan nilai rataan sebesar 4.9 dari 5.0 sangat efektif dalam mencari asisten laboran yang kompeten dan sesuai dengan nilai kriteria. Kedepannya metode ini juga dapat digunakan untuk sebagai acuan pengambilan keputusan dari beberapa kasus sesuai dengan indikator-indikator yang ditentukan. Sistem saat ini dapat dikembangkan dengan menambahkan soal untuk tes seleksi penerimaan asisten praktikum yang harus dijawab oleh mahasiswa sehingga bisa mengetahui peminatan yang cocok bagi mahasiswa.

\section{REFERENCES}

[1] Widiatry, "Rancang Bangun Website Sistem Informasi Praktikum Jurusan Teknik Informatika Universitas Palangkaraya,” J. Saintekom, vol. 6, pp. 12-24, 2016.

[2] M. Yumarlin, "Evaluasi Penggunaan Website Universitas Janabadra dengan Menggunakan Metode Usability Testing," J. Inf. Interaktif, vol. 1, no. 1, pp. 34-43, 2016.

[3] A. Andi Christian, Sebri Hesinto, "Rancang Bangun Website Sekolah Dengan Menggunakan Framework Bootstrap ( Studi Kasus SMP Negeri 6 Prabumulih )," SISFOKOM, vol. 07, pp. 22-27, 2018.

[4] A. N. Ompusunggu and L. Sitorus, "Sistem Pendukung Keputusan Seleksi Penerimaan Asisten Praktikum menggunakan Metode Fuzzy Tsukamoto," Media Inf. Anal. dan Sist., vol. 3, no. 2, pp. 185-189, 2018.

[5] Y. Sulviyana, A. Tejawati, and U. Hairah, "CALON ASISTEN PRAKTIKUM MENGGUNAKAN METODE SMART," Semin. Nas. Ilmu Komput. dan Teknol. Inf., vol. 2, no. 2, pp. 1-5, 2017.

[6] D. Kurniawaty, S. K. Sari, I. Cholissodin, F. Ilmu, and K. Universitas, "IMPLEMENTASI METODE NAÏVE BAYES CLASSIFIER UNTUK SELEKSI,”J. Teknol. Inf. dan Ilmu Komput., vol. 3, no. 4, pp. 273-278, 2016.

[7] A. Saleh, "PENERAPAN METODE SIMPLE MULTI ATTRIBUTE RATING TECHNIQUE EXPLOITING RANK DALAM SISTEM PENDUKUNG KEPUTUSAN REKRUTMEN ASISTEN LABORATORIUM KOMPUTER Application of Simple Multi Attribute Rating Technique Exploiting Rank Method in Decision Support System for," J. Masy. Telemat. dan Inf., vol. 8, no. 1, pp. 1-10, 2017.

[8] T. Mardiana, "SISTEM PENDUKUNG KEPUTUSAN PENERIMAAN ASISTEN LABORATORIUM KOMPUTER MENGGUNAKAN METODE AHP-TOPSIS,” J. ILMU Pengetah. DAN Teknol. Komput., vol. 3, no. 2, pp. 159-166, 2018.

[9] P. . Pungkasanti, "THE PRACTICAL ASSISTANT SELECTION DECISION SUPPORT SYSTEM USING PROFILE MATCHING," TRANSFORMATIKA, vol. 16, no. 2, pp. 175-181, 2019.

[10] H. Baibul Tujni, "Pengembangan Perangkat Lunak Monitoring Wellies dengan metode waterfall model," J. Ilm. Matrik, vol. 22, no. 1, pp. 122-130, 2020.

[11] F. Supandi, W. D. P, Y. Ambar, and S. Mat, "ANALISIS RESIKO PADA PENGEMBANGAN PERANGKAT LUNAK YANG MENGGUNAKAN METODE WATERFALL DAN PROTOTYPING .,” Semin. Din. Inform., vol. 2018, no. Senadi, pp. 83-86, 2018.

[12] L. Wali, M; Ahmad, "Perancangan Aplikasi Source code library Sebagai Solusi Pembelajaran Pengembangan Perangkat Lunak," J. Teknol. Inf. dan Komun., vol. 1, no. 1, 2017.

[13] A. D. L. Intan Putri Pratiwi, FX. Ferdinandus, "Sistem Pendukung Keputusan Penerima Program Keluarga Harapan (PKH) Menggunakan Metode Simple Additive Weighting," CAHAYAtéch, vol. 8, no. 2, 2019.

[14] I. J. T. Situmeang, S. Hummairoh, S. M. Harahap, and Mesran, "Application of SAW ( Simple Additive Weighting ) for the Selection of Campus Ambassadors," IJICS (International J. Informatics Comput. Sci., vol. 5, no. 1, pp. 21-28, 2021.

[15] S. K. Simanullang and A. G. Simorangkir, "Sistem Pendukung Keputusan Penerimaan Calon Karyawan Menggunakan Metode Simple Additive Weighting," TIN Terap. Inform. Nusant., vol. 1, no. 9, pp. 472-478, 2021.

[16] M. R. Ramadhan, M. K. Nizam, and Mesran, "Penerapan Metode SAW (Simple Additive Weighting) Dalam Pemilihan Siswa-Siswi Berprestasi Pada Sekolah SMK Swasta Mustafa," TIN Terap. Inform. Nusant., vol. 1, no. 9, pp. 459-471, 2021.

[17] J. Simarmata, T. Limbong, and M. Aritonang, "SISTEM PENDUKUNG KEPUTUSAN PEMILIHAN GURU BIDANG STUDI KOMPUTER MENGGUNAKAN METODE SIMPLE ADDITIVE WEIGHTING ( SAW )," CESS (Journal Comput. Eng. Syst. Sci., vol. 3, no. 2, pp. 186-190, 2018.

[18] T. Limbong et al., Sistem Pendukung Keputusan: Metode \& Implementasi. Medan: Yayasan Kita Menulis, 2020

[19] R. Y. Simanullang, Melisa, and Mesran, "Sistem Pendukung Keputusan Penerima Bantuan Covid-19 Menggunakan Metode Simple Additive Weighting (SAW)," TIN Terap. Inform. Nusant., vol. 1, no. 9, pp. 2-9, 2021.

[20] T. A. Kurniawan, "PEMODELAN USE CASE ( UML ): EVALUASI TERHADAP BEBERAPA KESALAHAN DALAM PRAKTIK USE CASE ( UML ) MODELING : EVALUATION ON SOME PITFALLS IN PRACTICES,” $J$. Teknol. Inf. dan Ilmu Komput., vol. 5, no. 1, pp. 77-86, 2018.

[21] N. Syahputri, J. K. L. Yossudarso, K. No, J. Teknik, and U. P. Utama, "RANCANGBANGUN MEDIA PEMBELAJARAN MATEMATIKA SEKOLAH DASAR KELAS 1 MENGGUNAKAN METODE DEMONSTRASI," J. Sist. Inf. Kaputama, vol. 2, no. 1, pp. 89-95, 2018.

[22] D. Susandi, "Sistem Penjualan Berbasis E-Commerce Menggunakan Metode Objek Oriented pada Distro Dlapak Street Wear," J. Sist. Inf., pp. 5-8, 2017. 